\title{
Huge Pleomorphic Adenoma of the Parapharyngeal Space
}

\section{Ballage A, Khdim M*, Douimi L, Abada R, Rouadi S, Roubal M and Mahtar M}

ENT Department and Head and Neck Surgery, Hospital August 20, 1953, Ibn Rochd Teaching Hospital, Casablanca, Morocco

*Corresponding author: Khdim M, ENT Department and Head and Neck Surgery, Hospital August 20, 1953, Ibn Rochd Teaching Hospital, Casablanca, Morocco, Tel : 0615372251, E-mail : Khdim02mouna@gmail.com

Citation: Ballage A, Khdim M, Douimi L, Abada R, Rouadi S, et al. (2019) Huge Pleomorphic Adenoma of the Parapharyngeal Space. J Case Rep Stud 7(4): 404. doi: 10.15744/2348-9820.7.404

Received Date: March 30, 2019 Accepted Date: August 27, 2019 Published Date: August 29, 2019

\begin{abstract}
Tumours of the parapharyngeal space are rare (less than $1 \%$ of head and neck tumours). They are of various etiologies, but pleomorphic adenomas from the parotid gland, nerve tumours and paragangliomas of the vagus nerve account for more than two thirds of cases.

We report a case of a huge pleomorphic adenoma of the parapharyngeal space in a 36-year-old male, the patient was operated on by cervical route, with complete removal of the tumor. The final anatomopathological examination concluded that there was a pleomorphic adenoma. The postoperative consequences were simple.
\end{abstract}

Keywords: Parapharyngeal Tumours; Salivary Glands; Pleomorphic Adenoma

\section{Introduction}

Tumours of the paraphagous space are rare, accounting for $0.5 \%$ of all tumours of the head and neck. Para pharyngeal space tumors (PPSTs) can be primary, metastatic, or extensions from adjacent structures. Most PPSTs are benign (70\%-80\%) including $40 \%$ to $50 \%$ originating from salivary glands [1]. Pleomorphic adenoma is the most common histological type [2]. They may be undetected for a long period of time, after which they usually present as an asymptomatic intraoral or cervical mass pushing oropharyengeal structures medially, change in voice, foreign body sensation in the throat, trismus, discomfort when swallowing, mass in the upper neck, cranial nerve deficits, obstruction of the Eustachian tubes, otaligia, and rarely obstructive sleep apnea [3]. Clinical symptomatology is poor, correlated with the mass effect of the tumor on adjacent structures [4,5]. The problems posed by these tumors are diagnostic and therapeutic. The situation deep and difficult to access for a biopsy or fine needle aspiration (FNA) imposes a fine analysis of preoperative imaging both on the etiological and topographical diagnosis. For these reasons, it's preferable to start investigations of these tumors with image scans that will show the characteristics of the lesion (such as vascularity and extensions). Therefore, we can use computer tomography CT as well as MRI, the latter being the most useful in these types of tumors because of its better definition of soft tissues [3].

The following report describes a case of huge primitive pleomorphic adenoma of the Para pharyngeal space and illustrates both diagnostic and therapeutic approach.

\section{Observation}

He is a 36-year-old man with no particular pathological history, who consulted us for a pharyngeal gene evolving for a year, then the evolution was marked by the installation of dysphagia associated with nocturnal snoring and rhinolalia without dyspnea or dysphonia. The examination of the oral cavity showed a regular bulging of the lateralized oropharynx on the left side (Figure 1). The neck examination did not find any swelling. The rest of the ENT and somatic examination was without anomalies. Face CT showed a voluminous tissue process occupying the left parapharyngeal space erasing the rosenmuller fossa reducing nasal and oropharyngeal light, this tumor extends laterally to the chewing space reaching the parotid space and back to the carotid space measuring approximately $70 \mathrm{X} 80 \mathrm{~mm}$ increasing heterogeneously after the injection of contrast material. Surgery has been indicated (Figure 2). The patient underwent cervical surgery. The incision used is of sibileau-carrega, the anterior edge of the sternocleidomastoid muscle was located, dissection of the internal jugular vein, XII and X was located, the axis is placed on lakes. Discovery of the mass on the deep face of the carotid axis, dissection of the tumor. After exposure of the mass, delivery of the tumour was easy and removal was complete (Figure 3). The definitive histological examination and immunohistochemitry confirmed the diagnosis of PA.There was no recurrence after a 1-year retreat . 


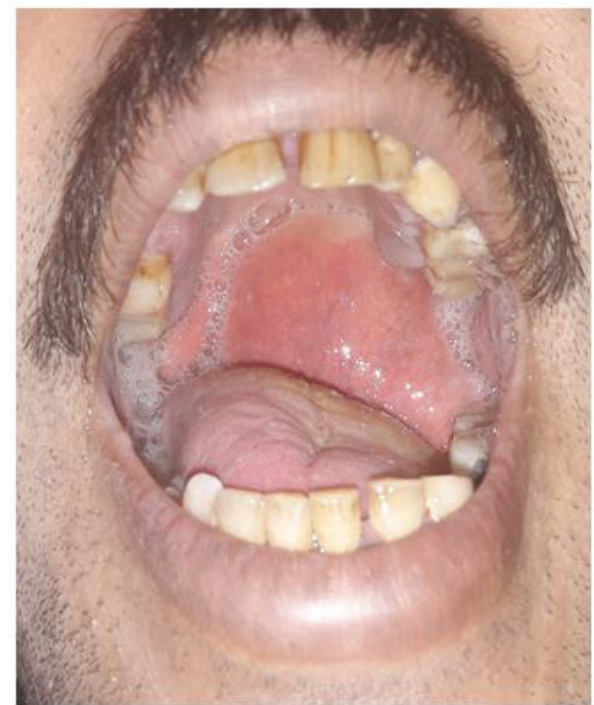

Figure 1: Regular Bulging of the Lateralized Oropharynx on the Left Side
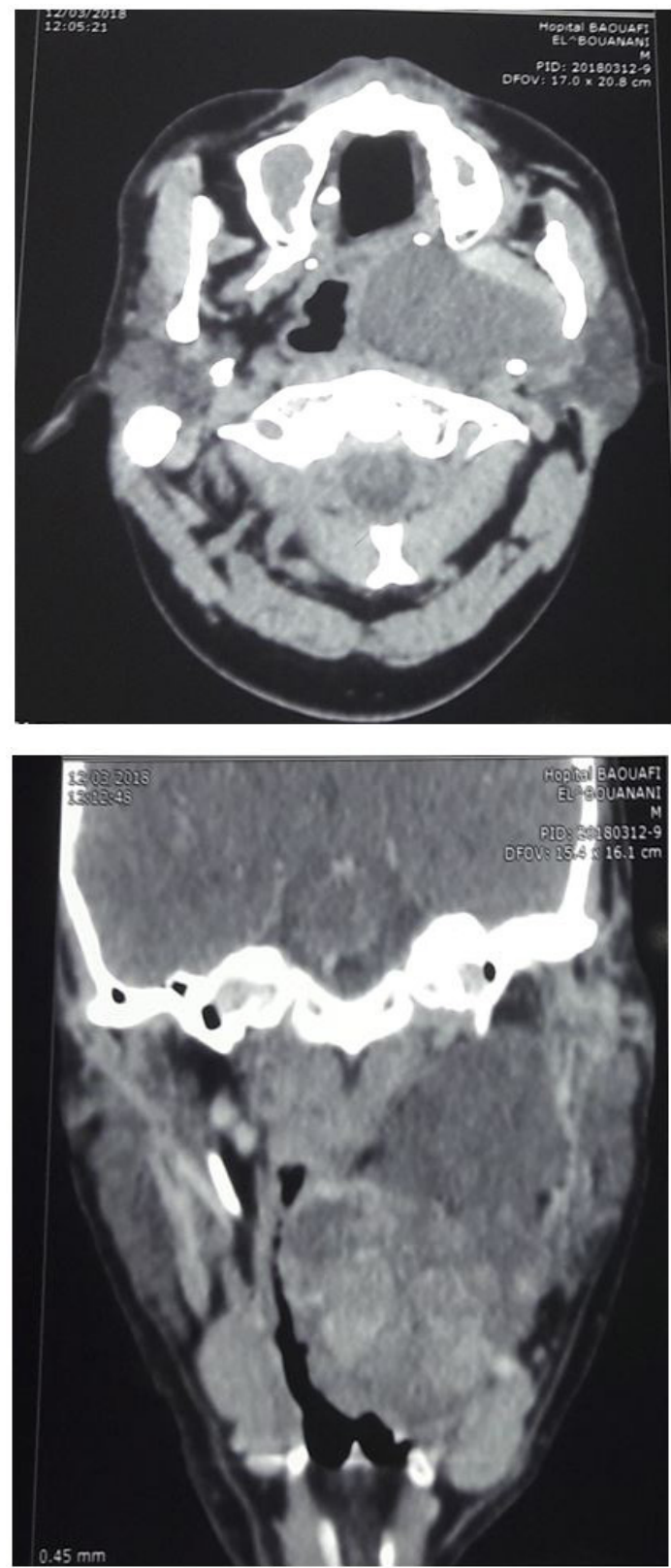

Figure 2: Axial and Coronal Section Scanner : Very Limited Mass Occupyong the Right Prestylian Space 

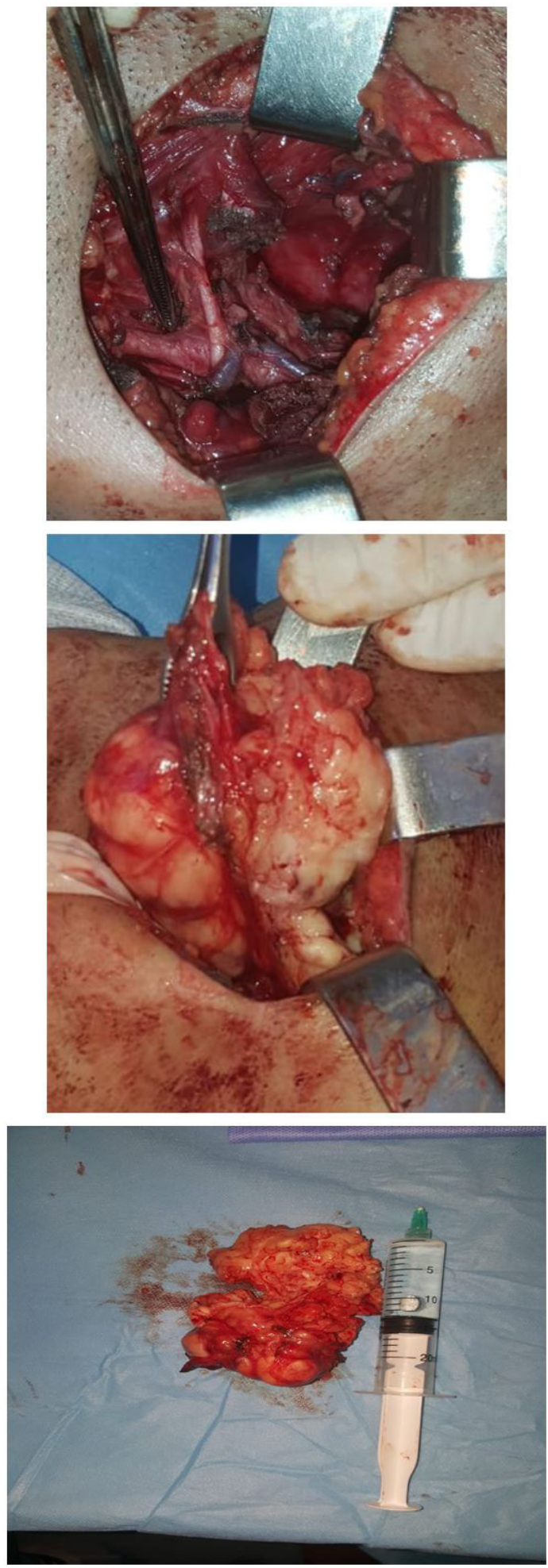

Figure 3: Cervical Surgery.

\section{Discussion}

Parapharyngeal space tumours are rare tumours representing approximately 0.5 to $1 \%$ of all tumours of the head and neck. A wide variety of benign and malignant tumours are described. Of those, benign tumors being the most frequent representing $80 \%$ with $40 \%$ to $50 \%$ originating from the salivary glands and $90 \%$ are pleomorphic adenomas. These tumors present similar distribution between genders, appear at an average of 50 years, and rarely show in the bilateral form [3]. The nature of tumors developed in the retropharyngeal space is different from those found in the lateropharyngeal space. Primary salivary tumours are the most frequent tumours in parapharyngeal spaces. They represent 40 to $50 \%$ of parapharyngeal tumours and $90 \%$ are pleomorphic adenomas $[1,5]$. 
Because of the deep location in the lateral pharyngeal space, these tumors remain silent for a long time since they grow slowly, with an average of 9 months from initial symptoms to a definitive diagnosis. Characteristically they appear as an intraoral expansive masse or an external mass bellow the mandible angle. They can also produce very varied symptoms because of the mass effect of the tumor on adjacent structures, such as dysphagia, pharyngeal gene, rhinolalia, snoring, discomfort when swallowing, local pain, and otalgia. Sleep apnea syndromes have also been reported due to the orophayngeal obstruction. However, when these lesions are accompanied by pain, trismus or neuropathies, we should consider a tumor with malignant etiology $[3,6]$ as dysphagia, pharyngeal discomfort, rhinolalia and snoring.

For diagnosis, it is advisable to start investigations with image scans to provide precise characteristics of the lesion. The CT scan is the first-line test because it is able to visualize the tissues of the Para pharyngeal space. CT makes it possible to differentiate, with a reliability of $75 \%$ to $90 \%$, a tumor located in the retrostylian compartment from a tumor in the prestylian compartment, to properly evaluate the bone framework in terms of pterygoid processes, vertebral bodies and the base of the skull. It detects the possible presence of calcifications. Contrast enhanced CT and MRI can be used, the latter being preferable as it offers useful information about the location of pleomorphic adenoma, and its extension. It better defines the soft tissue and the relationship with the internal carotid artery and adjacent structures [6].

The treatment of these tumors is essentially surgical. The transoral way, easy to realize, seems to be abandoned by many authors because of problems of vascular control. It still keeps an indication in prestylian tumors with moderate size and a greasy edging clearly visible.

The pure cervical incision, used in our case, can be used for both retrostylian and prestylian tumors independent of the deep lobe of the parotide. This approach provides adequate access to the tumor and allows good control of large vessels and cranial nerves. It can be expanded during the surgery to a cervico-parotid incision or mandibulotomy way. It doesn't require facial nerve dissection unlike the cervico-parotid way recommended by Oslen [7-9].

\section{Conclusion}

Tumours of the parapharyngeal space are rare. Diagnosis is often made at a late stage because of the slow evolution and the deep anatomical situation.

\section{References}

1.Makeieff M, Guerrier B (2012) Parapharyngeal tumors [Tumeurs parapharyngées]. EMC - Oto-Rhino-Laryngologie 7: 1-13.

2. Bozza F, Vigili MG, Ruscito P, Marzetti A, Marzetti F (2009) Surgical management of parapharyngeal space tumours: results of 10-year follow-up. Acta otorhinolaryngol ital 29: 10-5.

3. F Bouilloud, F Je'goux, A Caze, B Godey, G Le Clech (2008) Parapharyngeal tumors: Diagnosis and treatment [Tumeurs parapharyngées : diagnostic et traitement]. Ann Otolaryngol Chir Cervicofac $125: 181-7$.

4. Morita N, Miyata K, Sakamoto T, Wada T (1995) Pleomorphic adenoma in the parapharyngeal space. J oral maxillofac Surg 53: 605- 10.

5. Varghese BT, Sebastian P, Abraham EK, Mathews A (2003) Pleomorphic adenoma of minor salivary gland in the parapharyngeal space. World J Surg Oncol 1: 2.

6. Ruiz-Laza, Pedro Infante-Cossio, Alberto Garcia-Perla, Jose-Maria Hernandez-Guisado, Jose-Luis Gutierrez-Perez (2006) Giant Pleomorphic Adenoma in the Parapharyngeal Space: Report of 2 Cases J Oral Maxillofac Surg 64: 519-23.

7. Som PM, Curtin HD (1995) Lesions of the parapharyngeal space. Role of MR imaging. Otolaryngol Clin North Am 28: 515-42.

8. Carrau RL, Myers EN, Johnson JT (1990) Management of tumors arising in the parapharyngeal space. Laryngoscope 100: 583-9.

9. Pang KP, Goh CH, Tan HM (2002) Parapharyngeal space tumours: An 18 year review. J Laryngol Otol 116: 170-5.

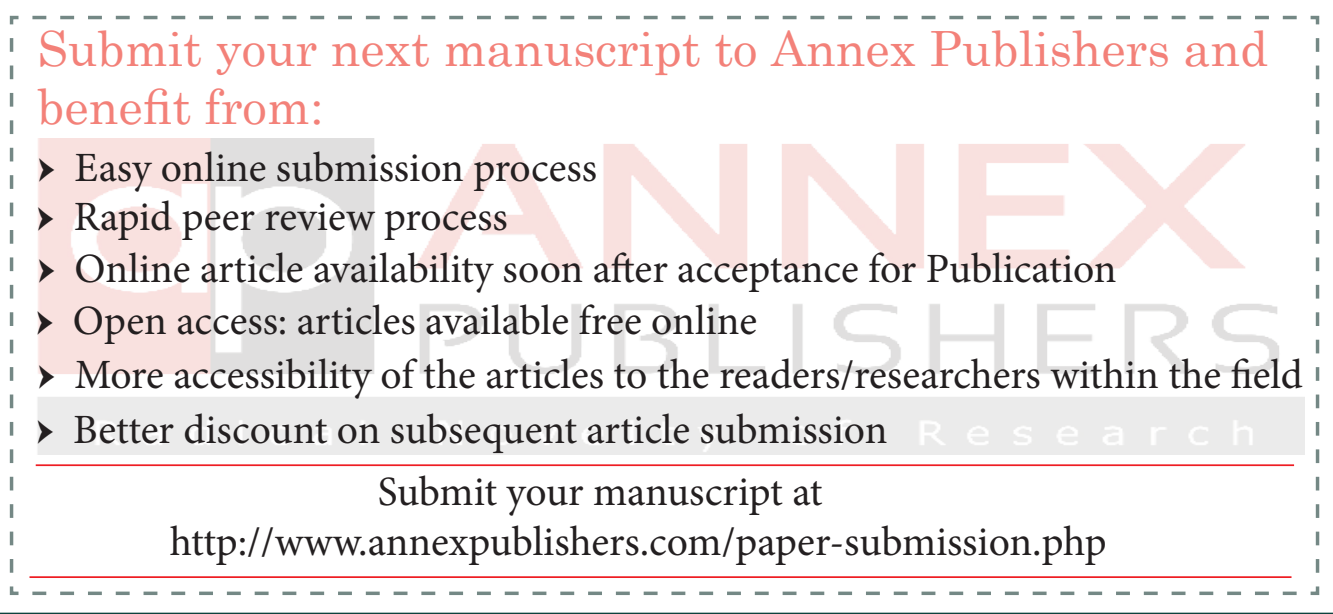

